\title{
PULMONARY AND CUTANEOUS TUBERCULOSIS: A SIMULTANEOUS PRESENTATION
}

\author{
Raza Ullah ${ }^{1}$, Shahida $\mathrm{Naz}^{2}$, Aamir Ahmad $^{3}$, Haleema ${ }^{4}$
}

\begin{abstract}
:
Mycobacterium tuberculosis is an aerobic organism causing a disease commonly called tuberculosis (TB). Skin involvement is rare especially in association with pulmonary TB. It involves skin in a number of ways. Most of the time they are confused with systemic disease causing involvement of both pulmonary and extra pulmonary organs. Diagnosing such cases are challenging and in almost all cases histological confirmation is necessary. We are presenting a case with erythematous nodular skin lesion on nose, cheeks and on her back near scapular area along with chest involvement.
\end{abstract}

KEYWORDS: Pulmonary, Cutaneous, Tuberculosis, Granulomatous Inflammation

How to cite this article:

Ullah R, Naz S, Ahmad A, Haleema. Pulmonary and Cutaneous Tuberculosis: A Simultaneous Presentation. Gandha Med Dent Sci. 2021;8(3): 60-63

DOI: https://doi.org/10.37762/jgmds.8-3.197

\section{Correspondence}

${ }^{1}$ Raza Ullah, Assistant Professor Pulmonology,

Hayatabad Medical Complex, Peshawar

Cell\# +92-333-9298991

Email:dr.raza127@gmail.com

${ }^{2}$ Senior Registrar Dermatology, PIMS Hospital,

Peshawar

${ }^{3}$ SPR Intensive Care, Hayatabad Medical Complex

Peshawar

${ }^{4}$ House Officer, Khyber Medical College, Peshawar

\section{INTRODUCTION:}

Tuberculosis is an infectious disease that is caused by a bacterium called mycobacterium tuberculosis ${ }^{1}$. It commonly involves pulmonary system but extra pulmonary involvement is not rare. Skin involvement is rare accounting for 1 $2 \%$, and occur in the form of lupus vulgaris, scrofuoderma, tuberculous chancre ${ }^{3}$ etc. simultaneous presentation of pulmonary and cutaneous tuberculosis is rare. Tissue diagnosis can be difficult as microscopy and culture are usually negative.

\section{CASE REPORT:}

This case is reported with in-written consent from patient. A 55 years old lady from Chitral presented to our clinic with exertional dyspnea, chest pain and skin lesion on face and trunk. Dyspnea was notable during exertion and chest pain was diffuse and centrally located. She was also complaining of non-productive cough usually at night. There was no fever but mild weight loss. She is hypertensive and is using amlodipine for BP control. Skin lesions were prominent on nose, cheek and trunk. They were erythematous nodular in appearance as shown in Figure 1.

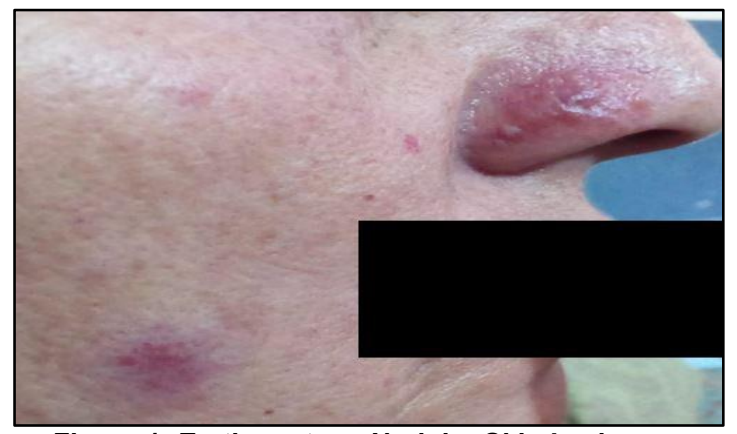

Figure 1: Erythematous Nodular Skin Lesion

Examination of the chest was notable for diffuse rhonchi and crepitation. There was no lymphadenopathy, clubbing, and edema. Skin lesions were non-tender and there was no evidence of infection in it. She was maintaining saturation. Chest X-ray was performed that showed bilateral infiltrates predominantly in the upper and lower zones. Bilateral hila were prominent suggestive of lymphadenopathy. Spirometry was performed 
that showed restrictive lung disease pattern (Figure 2). HRCT was performed that showed bilateral hilar lymphadenopathy, parenchymal infiltrates in the Broncho vascular pattern (Figure 3). Other blood investigations were normal except serum calcium in upper normal limit.

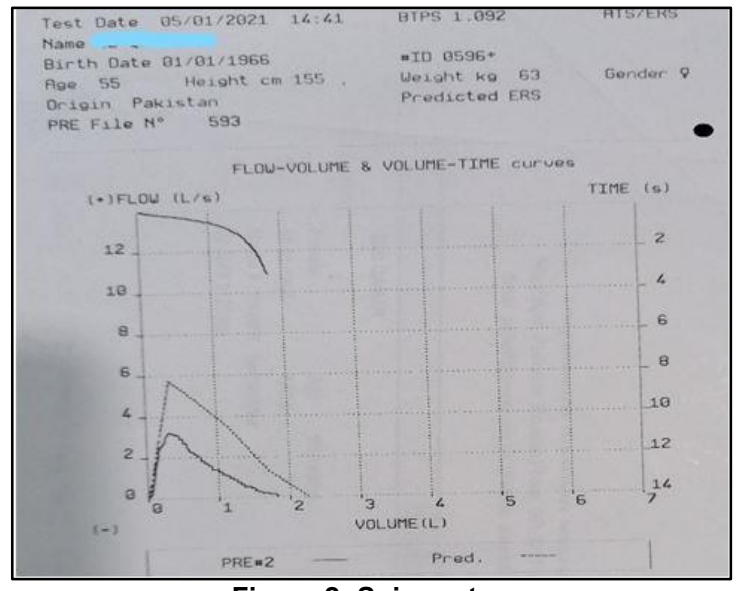

Figure 2: Spirometry

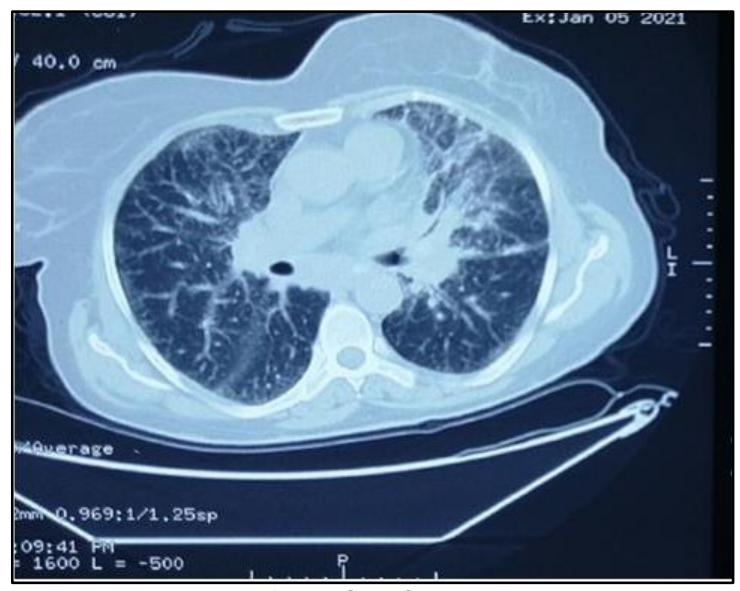

Figure 3: HRCT of the Patient

Diagnosis was not yet confirmed. Patient was started on inhalers and Panadol as needed and was encouraged to collect sputum for sputum AFB and gene Xpert but she failed to produce any sputum. Skin lesion biopsy was planned after discussing with dermatologist. Biopsy was taken from trunk lesion and sent for histopathology. Histopathology report (Figure 4) showed chronic granulomatous inflammation with no caseation. Granuloma consisted of epithelioid histiocytes and scattered multinucleated giant cells. Focally lymphocytes were seen in the center with neutrophils and peripheral rim of lymphocytes was present in many granulomas. ZN stain was negative for mycobacteria.

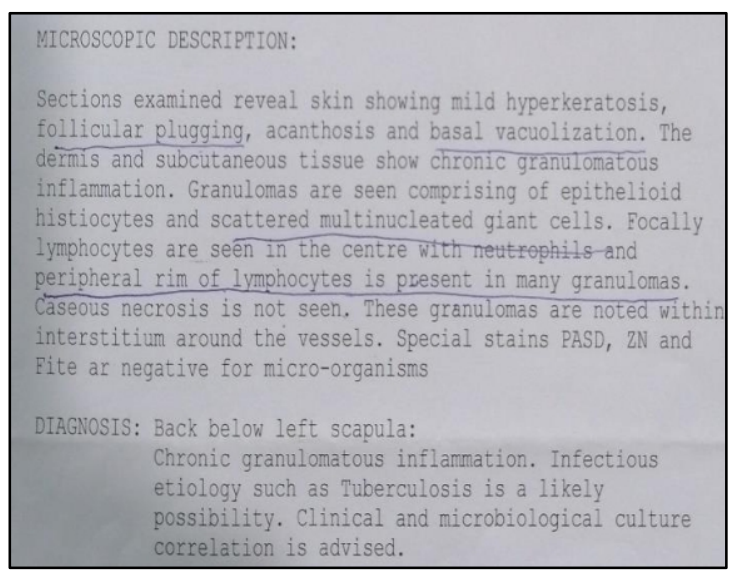

Figure 4: Histopathology Report of Biopsy

We were of the opinion to treat her as case of sarcoidosis but patient was again demonstrated with dermatology department. They advised to give trial of anti-tuberculous therapy (ATT) and see the result. Contrary to our expectations the patient responded well with disappearance of skin lesions, improvement in shortness of breath, chest pain and she gained weight of $5 \mathrm{~kg}$ after taking ATT for two months. She completed the course of ATT and now she has no complaint except mild Shortness of breath that is attributed to her past episodes of intermittent asthma (that was revealed later on inquiring for any chest problem in the past).

\section{DISCUSSION:}

Tuberculosis is a chronic disease caused by aerobic bacteria known as mycobacterium tuberculosis ${ }^{1}$. It commonly involves pulmonary system but extra-pulmonary manifestations are common. Cutaneous manifestation can be confused with other diseases with skin involvement. Diagnosing skin tuberculosis is very difficult because of its varying presentation and a wide range of differentials. Also the diagnosis itself is rare, as it is 
reported in less than $1-2 \%$ of tuberculosis infections ${ }^{4}$. The way the patient present the symptoms are important in reaching a specific diagnosis. Cutaneous TB presents with a variety of clinical manifestations like papules, chronic ulcers, verrucous plaques and nodules. It caneither be caused by hematogenous dissemination or from local inoculation into the skin $^{5}$. Specific cutaneous manifestations (e.g. lupus vulgaris, scrofuloderma, Tuberculosis cutis orificialis etc.) of M.tuberculosis depend upon many factors such as age, gender and general health status. Tuberculoid granuloma with variable amount of caseation is characteristics finding ${ }^{6}$. Other tests used for diagnosis are smear microscopy and culture.

In our patient the main differential was sarcoidosis. Sarcoidosis although predominantly involve pulmonary system, extra pulmonary manifestations are not rare and account for $25 \%$ of sarcoidosis ${ }^{7}$. Pulmonary manifestations include cough, shortness of breath and chest pain. Cutaneous sarcoidosis do present like lupus pernio, erythema nodosum, erythema multiform, skin pigmentation ${ }^{8}$ etc. Cutaneous sarcoidosis needs confirmation of noncaseation granuloma by histopathology of skin biopsy. Our patient histopathology produces further confusion by demonstrating noncaseating granuloma. One thing that favored TB was peripheral rim of lymphocytes around granuloma. In sarcoidosis sparse lymphocytic infiltrates surrounding granuloma has led to the term "Naked Granuloma". Other differentials are deep fungal infection, nocardiosis, syphilis, and leishmaniasis ${ }^{9}$.

Similar case report of cutaneous tuberculosis was presented by Brown et al. ${ }^{10}$ with similar lesion on wrist and biopsy was done that showed typical features of granuloma and the patient was treated with anti-tuberculous therapy. Similarly Sapmaz et al. ${ }^{11}$ presented a case of sternal tuberculosis diagnosed by histopathology of the lesion and successfully treated with anti-TB therapy although the duration of treatment was longer.

The duration of treatment for cutaneous tuberculosis is 6 months just like pulmonary TB. This multi-drug regimen includes two months of rifampicin, isoniazid, pyrazinamide and ethambutol followed by four months of isoniazid and rifampicin ${ }^{12}$. Our patient responded well to anti-TB therapy and completed the course successfully. Surgical excision is rarely needed in the treatment of cutaneous TB.

\section{CONCLUSION:}

This was a difficult case to diagnose because of its presentation like many other disease with cutaneous manifestations especially sarcoidosis and misdiagnosis could have devastating results. Skin lesions if present must be biopsied to confirm the diagnosis irrespective of disease presentations.

\section{CONFLICT OF INTEREST: None}

\section{FUNDING SOURCES: None}

\section{REFERENCES:}

1. World Health Organization. Tuberculosis [Internet]. Available from: https://www.who.int/healthtopics/tuberculosis\#tab=tab_1

2. Talwar A, Tsang CA, Price SF, Pratt $\mathrm{RH}$, Walker WL, Schmit KM, et al. Tuberculosis - United States, 2018. MMWR Morb Mortal Wkly Rep. 2019;68:257-62.

3. Khondker L, Wahab F, Nasim R, Mahmud $H$. Cutaneous tuberculosis with uncommon presentation: A case report and review of literature. $\mathrm{J}$ Pak Assoc Dermatol. 2020 Aug 7; 30(1):190- 7.

4. Machan A, Hanafi T, Hjira N, Boui M. Tuberculous gummas: epidemiological, clinical, bacteriological, immunological, and therapeutic features. Int $\mathrm{J}$ Mycobacteriol. 2018;7:203.

5. Mei $\mathrm{Y}$, Zhang $\mathrm{W}$, Shi $\mathrm{Y}$, Jiang $\mathrm{H}$, Chen Z, Chokkakula S, Long S, Pan C, Wang $\mathrm{H}$. Cutaneous tuberculosis and nontuberculous mycobacterial infections at a national specialized hospital in China. Acta dermatovenereologica. 2019 15;99(11-12) :997-1003.

6. Coondoo A, Das A. Essentials of dermatology and sexually transmitted diseases: An illustrated synopsis. Ind J Dermatol, Venereol, and Leprol. 2018;84(5):64-3. 
nontuberculous mycobacterial infections at a national specialized hospital in China. Acta dermatovenereologica. $2019 ; 99(11-12)$ : 997 -1003.

7. García-Colmenero L, Sánchez-Schmidt JM, Barranco C, Pujol RM. The natural history of cutaneous sarcoidosis. Clinical spectrum and histological analysis of 40 cases. International J Dermatol. $2019 ; 58(2): 178-84$.

8. Marcoval J, Penín RM, Mañá J. Histopathological features of subcutaneous sarcoidosis. The American J f Dermatopathol. 2020; 42; 42(4):233 43.
9. Wu Q. Andrews' diseases of the skin: Clinical dermatology. $J$ the Am Acad Dermatol. $2019 ; 81(6): \mathrm{e} 187$.

10. Brown $A E$, Ibraheim MK, Petersen E, Swaby MG, Pinney SS. An evolving presentation of cutaneous tuberculosis. Dermatol Online J. 2020;26(8):10.

11. Torquato MF, Costa MK, Nico MM. Cutaneous sarcoidosis: clinicoepidemiological profile of 72 patients at a tertiary hospital in São Paulo, Brazil. Anais brasileiros de dermatologia. 2020 ;95(1):57 -62.

12. Chen $Q$, Chen W, Hao F. Cutaneous tuberculosis: a great imitator. Clinics in Dermatology. $2019 ; 37(3): 1929$.

\section{CONTRIBUTORS}

1. Raza Ullah - Concept \& Design; Data Acquisition; Drafting Manuscript

2. Shahida Naz - Data Acquisition; Data Analysis/Interpretation; Drafting Manuscript

3. Aamir Ahmad - Critical Revision; Supervision; Final Approval

4. Haleema - Data Analysis/Interpretation; Drafting Manuscript

LICENSE: JGMDS publishes its articles under a Creative Commons Attribution Non-Commercial Share-Alike license (CC-BY-NC-SA 4.0). COPYRIGHTS: Authors retain the rights without any restrictions to freely download, print, share and disseminate the article for any lawful purpose. It includes scholarly networks such as Research Gate, Google Scholar, LinkedIn, Academia.edu, Twitter, and other academic or professional networking sites. 